\title{
EL PROYECTO TRIUNFOS BARROCOS: EL ESTUDIO DE LA FIESTA RENACENTISTA Y BARROCA EN EL GRUPO IHA (UNIVERSITAT JAUME I)
}

\author{
INMACULADA RODRÍGUEZ MOYA \\ Universitat Jaume I \\ VÍCTOR MÍNGUEZ CORNELLES \\ Universitat Jaume I
}

\section{RESUMEN}

El grupo Iconografía e Historia del Arte (IHA) de la Universitat Jaume I desarrolla desde hace veinte años una intensa labor en la Historia del Arte y, en concreto, en estudios iconográficos. Uno de sus proyectos principales de los últimos diez años ha sido Triunfos Barrocos. Este proyecto tiene como objetivo principal localizar, clasificar, analizar y editar las manifestaciones gráficas del arte festivo barroco en todos los territorios que formaron parte de la Monarquía Hispánica. Con esta finalidad ya han sido publicados seis volúmenes dedicados a los distintos reinos de la corona española, más un séptimo volumen recopilatorio.

Palabras clave: Fiesta, Monarquía Hispánica, Iconografía, Renacimiento, Barroco.

\section{ABSTRACT}

The Iconography and History of Art (IHA) Research Group, at the Universitat Jaume I, has been doing an intense work in Art History for twenty years and, in particular, in iconographic studies. One of his main projects of the last ten years has been 
Baroque Triumphs. The main objective of this project is to locate, classify, analyze and edit the graphic manifestations of Baroque festive art in all territories that were part of the Hispanic Monarchy. For this purpose, six volumes dedicated to the different kingdoms of the Spanish crown have already been published, plus a seventh compilation volume.

Keywords: Festivals, Hispanic Monarchy, Iconography, Renaissance, Baroque.

\section{LA LABOR Y EL CRITERIO METODOLÓGICO DEL GRUPO IHA}

El Grupo IHA (Iconografía e Historia del Arte) es un grupo que ha integrado desde su creación en 1991 a los profesores que se han ido incorporando al área de Historia del Arte en la Universitat Jaume I. Desde esa fecha hasta el año 1995, estuvo formado únicamente por el profesor Víctor Mínguez, único profesor del área, pero en el año 1996 se incorporó otro investigador. En el año 2000 el número de miembros ya ascendía a cuatro. Precisamente por estas fechas la Oficina de Ciencia y Tecnología de la UJI (OCIT) estableció un registro de grupos de investigación. Es entonces cuando surgió el grupo «Historia del Arte», que posteriormente cambió su nombre a «Iconografía y Arte». En 2014, 2017 y 2018 recibió el reconocimiento como Grupo de Investigación de Alto Rendimiento por la UJI y en 2019 una subvención por ser grupo de investigación activo en la captación de recursos. En 2016 recibió el VI premio Banco Santander a la Divulgación Científica en la Universitat Jaume I. En la actualidad el grupo lo constituyen Víctor Mínguez como investigador principal, Inmaculada Rodríguez Moya, Pablo González Tornel, Juan Chiva Beltrán, Luis Vives-Ferrándiz y Vicent Zuriaga-Senent dentro del consejo de investigadores, dieciséis investigadores entre profesores asociados doctores, investigadores postdoctorales e investigadores predoctorales. El grupo se completa con un investigador Honoris Causa, Fernando Checa, de la Universidad Complutense y con un Consejo de Asesores Externos formado por cinco catedráticos y titulares de reconocido prestigio. Además, el grupo tiene vínculos con otros relevantes grupos de investigación, formando parte por ejemplo del grupo MAPA (Magnificencia, Arte y Poder) con la Universidad Complutense y la Universidad de Valladolid, integrándose también en dos nodos de la Red Columnaria, entre otros.

Como grupo que aglutina a todos los componentes del área de Historia del Arte, este grupo coordina todas las actividades que se han llevado y se llevan a cabo en la UJI desde este ámbito de conocimiento: cursos de verano 
ininterrumpidamente desde 1996, jornadas y seminarios como los ciclos de conferencias en el Aula Isabel Ferrer, las conferencias inaugurales del programa de Doctorado en Historia del Arte, las jornadas de arte valenciano, seminarios IHA, treinta y siete workshops internos en los que se discuten los trabajos de los investigadores, campos de restauración, etcétera. El grupo también se encarga de la dirección de la Revista Potestas. Estudios sobre el Mundo clásico e Historia del Arte, que va por su número 17 desde el año 2008 (Fig. 1). El equipo investigador que lleva a cabo esta investigación lleva treinta años volcado en el análisis del significado de las imágenes de la Edad Moderna -no solo plásticas, también arquitectónicas y urbanísticas-, especialmente las vinculadas a la imagen del poder, recurriendo para ello fundamentalmente a dos metodologías complementarias: la historia de la cultura y el método iconográfico-iconoló-

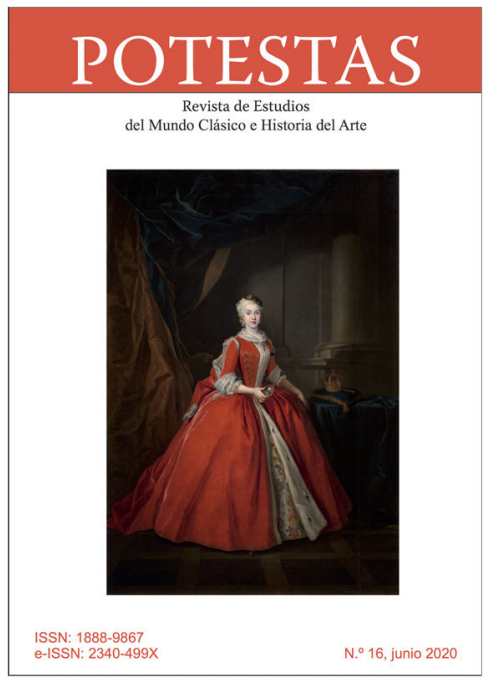
gico, ambas nacidas en Alemania a mediados del siglo XIX y principios del XX respectivamente.

Entre todas sus actividades destaca la serie de congresos especializados denominados Simposios «Iconografia y Forma: Visiones», que acaba de celebrar su séptima edición. Estos congresos han permitido reunir en la Universitat Jaume I a un amplio número de especialistas, $\mathrm{y}$ han dado lugar a la edición de varios libros que han recogido las ponencias presentadas a cada uno de los encuentros. El equipo de directores de este simposio, que firman este artículo, ha dirigido esta serie de congresos internacionales en los que se ha debatido sobre la Historia del Arte y la Arquitectura, desde esa mirada interdisciplinar y desde la metodología de la Historia de la Cultura. De este modo hasta el momento han tenido lugar siete encuentros. Todos ellos se desarrollaron como un debate de alta especialización donde intervinieron ponentes de reconocido prestigio internacional.

En el año 2005 se celebró el primero, Visiones de la Monarquía Hispánica, debatiéndose sobre diversos temas de iconografía regia, con especial énfasis en aspectos como regiofanías, taumaturgias, representaciones bíblicas o celestiales, simbolismo político, espacios regio-sacros, etcétera. En el año 2008 tuvo lugar el segundo, dedicado a las Visiones utópicas de la ciudad, una propuesta que nos pareció muy oportuna en el momento académico y social actual, en el que 
la reflexión sobre la ciudad y su desarrollo futuro están a la orden del día. En ambos ámbitos fue oportuno reflexionar sobre los modelos utópicos y sus representaciones plásticas desde la Edad Media hasta el siglo XX a nivel mundial. En este congreso se analizaron las visiones utópicas de la ciudad, desde las puramente artísticas, como la corografía o las vistas idealizadas o imaginadas, hasta aquellas que suponían importantes transformaciones e innovaciones urbanísticas y arquitectónicas. En el año 2010 el tercer encuentro se centró en las Visiones hispánicas de otros mundos, analizándose la producción artística relacionada con la gran amplitud espacial del Imperio español. Se tuvo especial interés en las representaciones artísticas que, emanadas desde la península ibérica y desde las posesiones europeas y los virreinatos americanos, contemplaron a otros mundos -América, Asia, África... e incluso a la propia Europa culturalmente diversa-, ya que la visión que desde el Imperio se tuvo de otras tradiciones culturales y artísticas nunca fue superficial, como pone de relieve el carácter pionero de la monarquía española en las exploraciones, evangelizaciones y el interés por el conocimiento de mundos distintos y lejanos.

En el año 2013, el simposio Visiones de Pasión y Perversidad reflexionó sobre representaciones figurativas del amor, de la sexualidad y de la perversión desde el mundo antiguo hasta la contemporaneidad, y especialmente en su relación con el poder. La puesta en común de diversas investigaciones en torno a la iconografía y las visiones plásticas de Eros y Anteros, Venus, Ninfas, y otros personajes de la mitología, así como reyes, gobernantes, personajes históricos e incluso visiones costumbristas, permitió ahondar en el conocimiento de una Historia del Arte muchas veces oculta o subterránea por los convencionalismos sociales de las diferentes épocas.

En el año 2015, el simposio Visiones de un Imperio en Fiesta abordó con los máximos exponentes mundiales del estudio sobre la fiesta barroca, como Andrea Sommer-Mathis, Agnès Guiderdoni, Nuno Senos, Giovanni Muto o Teresa Zapata Fernández de la Hoz, los estudios sobre la fiesta y el arte efímero durante el Renacimiento y el Barroco, y sus repercusiones durante la Edad Contemporánea, así como la importancia de los mismos en el avance de los estilos artísticos (Fig. 2). Desde el mundo de la iconografía, desde los estilos arquitectónicos o desde la imagen del poder, autores como Aby Warburg, Erwin Panofsky, Santiago Sebastián, Marcello Fagiolo, Roy Strong, Víctor Mínguez, José Miguel

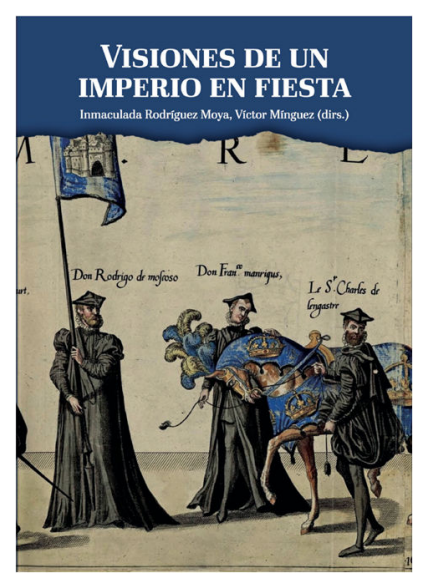


Morales Folguera o Fernando Checa han analizado diversos festejos, marcando la importancia de los mismos en el mundo cortesano y profundizando en la producción artística de los mismos, desde las máquinas efímeras descritas por las relaciones festivas, a los grabados y lienzos que evocan el apasionante mundo de la fiesta barroca.

En el 2018 se celebró bajo el título Visiones de Inmaculadas, reliquias y santos, en el que las rigurosas sesiones científicas orbitaron alrededor de la idea de las devociones y milagros vinculados a la Casa de Austria. Buscando legitimar su acción política, los Habsburgo aspiraron a la sacralización de sus acciones, fijando la asunción de un Planeta Católico dirigido bajo su férula como el gran objetivo a lograr. De esta forma se desplegaron estrategias como la evangelización de América, la lucha contra turcos y protestantes, la acumulación de reliquias o la obsesión por lograr que un rey del linaje fuese canonizado. Todos estos temas fueron tratados por destacados académicos como Fernando Checa, J.J. Ruíz Ibáñez, Antonio Álvarez-Osorio, Wifredo Rincón, Agnés Guiderdoni o Friedrich Polleross.

Finalmente, en 2020 hemos celebrado el VII Simposio Internacional «Iconografia y forma: Rex Bellum. Visiones artísticas de guerra y conquista. Aristóteles definió el concepto de guerra legítima -Ius ad bellum-, y su discípulo Alejandro conquistó Asia. Desde Cicerón y San Agustín hasta Maquiavelo y Clausewitz, muchos pensadores, tratadistas y autores de «espejos de príncipes» defendieron las virtudes y las ventajas de la guerra. Y durante siglos monarcas y emperadores construyeron estados e imperios en Europa librando contiendas contra rivales y enemigos. El prestigio de la victoria permitió fabricar en cada ocasión una determinada iconografía de la guerra que se desplegó en los retratos regios, los palacios, las ciudades o la fiesta pública, construyendo ininterrumpidamente y por doquier artefactos visuales de gran poder persuasivo que han pervivido hasta la cultura artística contemporánea. Si la Imitatio Alexandri llevó a muchos príncipes a pretender emular la memoria y la grandeza del rey de Macedonia a través de la gesta militar, algunos de ellos a su vez -Julio César, Carlomagno, Carlos V de Habsburgo, Jean Sobieski de Polonia, Federico el Grande de Prusia o Napoleón, por citar algunos de los más relevantes- se convirtieron en modelo para otros muchos monarcas belicistas a lo largo de la Historia. Este congreso ha reunido en la Universitat Jaume I y a través de la plataforma Google Meet en octubre de 2020 a muchos de los especialistas de mayor relevancia en el estudio de las representaciones del poder para que puedan presentar y debatir sus hipótesis y metodologías de análisis sobre los mecanismos de fabricación de la imagen del Rey Guerrero durante siglos y establecer los modelos y categorías de mayor impacto en el Arte Occidental: Fernando R. de 
la Flor, Fernando Checa, Matteo Mancini, Miguel Ángel Zalama, Concepción Porras, Jesús F. Pascual Molina, Carmen Morte, Friedrich Polleross, Marina Viallon, Manfredi Merluzzi, Flavia Tudini, etcétera.

Fruto de estos congresos han sido las siguientes publicaciones:

VISIONES DE LA MONARQUÍA HISPÁNICA

Victor Mínguez (ed.)

Publicaciones de la Universitat Jaume I, Castelló de la Plana, 2007.

Colección América, $n^{\circ} 8$

348 págs.

ISBN: 978-84-8021-593-0

EL SUEÑO DE ENEAS. IMÁGENES UTÓPICAS DE LA CIUDAD

Víctor Mínguez, Inmaculada Rodríguez, Vicent Zuriaga (eds.)

Biblioteca Valenciana, Generalitat Valenciana.

Universitat Jaume I, 2009.

265 págs.

ISBN 978-84-8021-710-1

ARTE EN LOS CONFINES DEL IMPERIO. VISIONES HISPÁNICAS DE OTROS MUNDOS

Inmaculada Rodríguez / Víctor Mínguez (eds.)

Universitat Jaume I, Castellón, 2011.

373 páginas.

ISBN: 978-84-8021-797-2.

VISIONES DE PASIÓN Y PERVERSIDAD

Víctor Mínguez e Inmaculada Rodríguez Moya

Fernando Villaverde Ediciones, Madrid, 2014

272 páginas.

ISBN/ISSN: 978-84-616-9796-0

VISIONES DE UN IMPERIO EN FIESTA

Inmaculada Rodríguez Moya, Víctor Mínguez Cornelles (eds.)

Fundación Carlos de Amberes Madrid, 2016

396 páginas, ilustraciones a color

ISBN: 978-84-87369-74-2

LA PIEDAD DE LA CASA DE AUSTRIA. ARTE, DINASTÍA Y DEVOCIÓN

Víctor Mínguez e Inmaculada Rodríguez (dirs.) 
Ediciones Trea, Col. Piedras Angulares

317 páginas, ilustraciones en color.

ISBN 978-84-17140-66-3

REX BELLUM. VISIONES ARTÍSTICAS DE GUERRA Y CONQUISTA.

Inmaculada Rodríguez y Víctor Mínguez (dirs.)

Ediciones Trea.

En prensa.

\section{EL PROYECTO TRIUNFOS BARROCOS: UNA LABOR DE EQUIPO EN TORNO A LA FIESTA}

Sin lugar a dudas, dentro de esta gran línea de investigación iconográfica del grupo IHA, ha sido el proyecto Triunfos Barrocos y toda la investigación individual sobre el arte efimero que se ha derivado del mismo, el que más alcance ha tenido en los últimos diez años. En el año 2009 el grupo de investigación IHA puso en marcha, bajo la dirección de Víctor Mínguez, el proyecto Triunfos Barrocos, con un ambicioso propósito: localizar, clasificar, analizar y editar las manifestaciones gráficas del arte festivo barroco en todos los territorios que formaron parte de la Monarquía Hispánica. El proyecto surge de la necesidad de contar con un proyecto de largo alcance que cohesionara definitivamente a un grupo que en esos momentos ya estaba consolidado y reforzado, pero que permitiera realizar un trabajo en un campo común de investigación en el que todos sus integrantes se sintieran cómodos y participaran con ilusión. Dado que las líneas de investigación dominantes de los miembros del grupo IHA eran la iconografía y la arquitectura de la Edad Moderna, era lógico que el campo idóneo que interesara a todos fuese el arte festivo. Más aún cuando, Víctor Mínguez, su director contaba ya con una larga experiencia en la investigación de lo efímero.

El proyecto Triunfos Barrocos se ha convertido desde entonces en el buque insignia del grupo y, por tanto, su diseño se ha ideado con ambición, tanto en el objeto de estudio, donde se pretende abordar la fiesta barroca en todos los reinos y territorios de la monarquía española, como en la presentación de los resultados, con la creación de una colección o proyecto editorial de alta calidad. El objetivo final consiste en poner al abasto de los investigadores y estudiosos de la Edad Moderna, pero también para un público general amante de ediciones de calidad o bibliófilos, una serie de volúmenes de gran formato que ofrezca un catálogo completo de las imágenes publicadas en los libros de fiestas, pero también diseños, esbozos, acuarelas sueltas, lienzos y otras imágenes 
complementarias de la fiesta, de los siglos XVI a XVIII. Cada volumen ha supuesto un trabajo de aproximadamente dos años, puesto que dicha labor se estructura en el diseño de un índice, recopilación de imágenes, clasificación, análisis y estudio de fuentes e imágenes, así como la redacción y edición del libro. El director del proyecto general es Víctor Mínguez, pero cada volumen se confía a un coordinador específico, buscando su especialización en el territorio a tratar.

La metodología que se ha empleado y emplea para realizar esta investigación es la Historia de la Cultura, un método que tiene en cuenta diferentes corrientes historiográficas de la Historia del Arte para realizar un análisis lo más completo posible, y que tenga en cuenta aspectos históricos, sociales, culturales, económicos, además de los puramente artísticos. Es decir, partimos del análisis iconográfico de las imágenes teniendo en cuenta sus modelos o referentes icónicos, para analizar después su contenido temático, la escena representada, los elementos simbólicos y alegóricos, y su significado. Finalmente se tiene en cuenta el contexto histórico y social, la mentalidad que estas imágenes reflejan, los referentes literarios, para comprender toda la significación de las mismas, su trascendencia y su importancia, y su valor histórico y político. Todo ello porque consideramos a la obra de arte, incluso la efímera, como algo aislado en el tiempo y en el espacio, sino que tenemos en cuenta el descubrimiento de Warburg del «viaje de las imágenes», es decir, su inspiración en fuentes de la Antigüedad, sus viajes de ida y vuelta por continentes y épocas.

El estudio de la fiesta al que Burckhardt dedicó un gran interés en sus estudios de Historia Cultural, ha sido del mismo modo parte esencial de las investigaciones del grupo, puesto que aglutina como ninguna otra manifestación artística los valores ideológicos y culturales de una sociedad, e igualmente se manifiesta en todas las posibilidades creativas: arquitecturas efímeras, lienzos, esculturas, literatura, teatro, paradas, entretenimientos, músicas, etcétera. Hemos considerado en nuestra investigación sobre la fiesta tanto sus fuentes literarias como sus testimonios gráficos, y los escasos materiales emblemáticos $\mathrm{y}$ arquitectónicos conservados.

En esta pesquisa aplicamos nuestra propia propuesta metodológica, que podemos definir como un sistema de interpretación de las imágenes basado en la búsqueda de fuentes documentales e iconográficas de todo tipo, incluyendo significativamente las emblemáticas, y en un posterior análisis realizado a partir de la imbricación de la obra de arte con la historia y la cultura del periodo. Pero apoyado también en la integración de las propias artes, el influjo recíproco entre pintura, escultura, arquitectura, grabado, arte efímero, artes suntuarias, etcétera. 
Asimismo, se fundamenta en el análisis estético y formal de las obras de arte desde la óptica del pasado y desde una mirada más actual, teniendo presente siempre la noción de la vida y del viaje de las imágenes. Ello nos obliga a la necesaria interdisciplinariedad del método, y al encuadramiento de este método como una síntesis entre el de la Historia del Cultura y el Iconográfico-Iconológico.

El arte efímero y su iconografía han sido un tema capital de la cultura moderna, que permite comprender adecuadamente cómo se manipularon e instrumentalizaron las imágenes artísticas y los resortes propagandísticos de la fiesta, para asegurar la lealtad de los súbditos hacia el monarca y hacia su religión. Por ello, la fiesta en el Renacimiento y el Barroco ha constituido una línea muy fecunda en las líneas de investigación de la universidad española en los últimos treinta y cinco años. Hoy en día, además, es una línea de gran vigor que aborda también otros aspectos del arte efímero como la cultura emblemática y alegórica asociada a este, y más recientemente la reconstrucción virtual -tanto arquitectónica como cromática- de sus estructuras y sus decoraciones. Durante más de cuatro décadas historiadores del Arte, historiadores de la Literatura y de la Historia Moderna, tanto españoles, como colegas iberoamericanos y colegas extranjeros hispanistas, se han volcado en el estudio de lo efímero, siguiendo el camino de pioneros como Karl Ludwig Selig, Giuseppina Ledda, Julián Gállego, Aquilino Sánchez Pérez, Yves Bottineau, Antonio Bonet Correa y Santiago Sebastián.

\section{DE LA ILUSIÓN A LA CONSOLIDACIÓN DEL PROYECTO}

Dado que para el primer volumen, que iniciamos en el año 2009, nos enfrentábamos a la incerteza de su posibilidad y de su recepción, escogimos para empezar el territorio más próximo y mejor conocido por el equipo: el Reino de Valencia. Ello nos facilitaba también, por ejemplo, contar con un corpus de imágenes de partida considerable debido a que el reino contó durante los siglos XVII y XVIII con una potente industria editorial, que conocíamos bien. Así, en el año 2010 salió a la luz el primer volumen, fruto de esta investigación: La fiesta barroca. El reino de Valencia (1599-1802) (Fig. 3), cuya autoría fue de Víctor Mínguez, Pablo

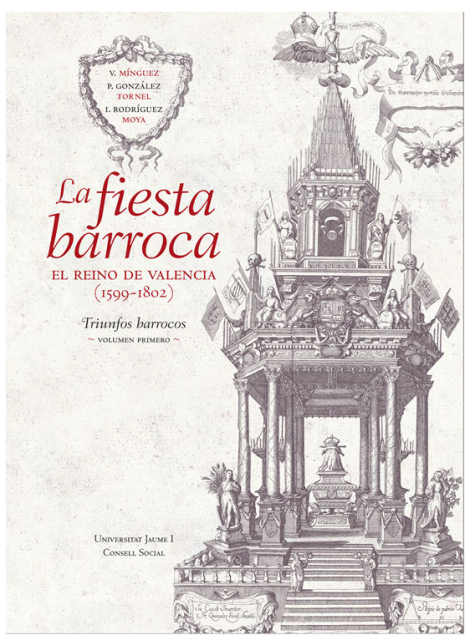


González e Inmaculada Rodríguez, y fue editado gracias al mecenazgo del Consejo Social de la UJI. Se presentó en la sede del Consejo Social de la UJI en diciembre de ese mismo año. Este volumen fue coordinado por Pablo González Tornel. Constó de seis capítulos y un catálogo de trescientas ochenta y dos imágenes, así como un listado actualizado de fuentes esenciales y bibliografía. El apoyo de nuestra editorial universitaria permitió una alta calidad editorial y que pronto además contara con una versión electrónica, nivel editorial y novedades técnicas que se consolidaron en los futuros volúmenes.

En el año 2012 apareció el segundo volumen, La fiesta barroca. Los virreinatos americanos (1560-1808), publicado conjuntamente por la Universidad de las Palmas de Gran Canaria y la Universitat Jaume I y coordinado por Inmaculada Rodríguez Moya, incorporando además al equipo del primer volumen, a Juan Chiva Beltrán (Fig. 4). Este segundo volumen respondía a la satisfacción que produjo la edición del primero y, sobre todo, a que decidimos abordar un territorio conocido también por los autores. Varios miembros del grupo tienen una acreditada trayectoria americanista a través de publicaciones y participaciones en congresos y,

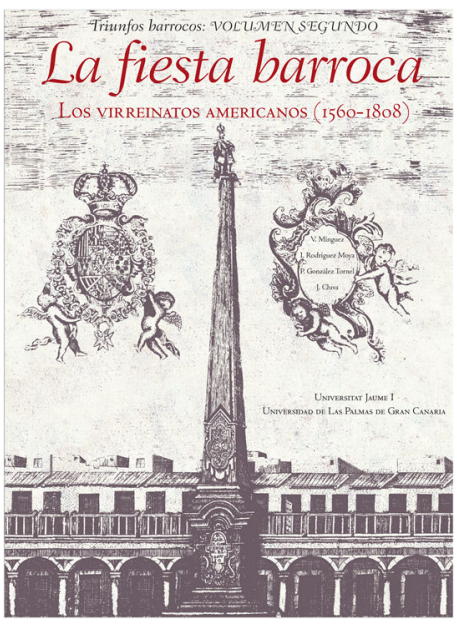
por tanto, decididos investigar el arte festivo engendrado en los cuatro virreinatos transatlánticos del imperio, con las dificultades que suponía recopilar imágenes y fuentes de un territorio tan amplio, distante y diverso. El estudio se estructuró en ocho capítulos y un catálogo de cuatrocientas treinta y ocho imágenes, agrupadas en dos bloques: el virreinato de la Nueva España y los virreinatos del Perú, Nueva Granada y Río de la Plata. La aportación de la obra fue reunir tanto la mayor parte de las imágenes -algunas inéditas-como una mirada global e independiente, frente a las aportaciones del arte festivo americano con un enfoque regional, a pesar de la importancia de algunas de estas investigaciones previas. El volumen fue presentado en septiembre de 2012 en el marco del XIX Congreso Nacional de Historia del Arte CEHA, celebrado precisamente en la Universitat Jaume I. Este libro obtuvo en 2013 el premio a la Mejor Coedición Interuniversitaria de los XVI Premios Nacionales de Edición Universitaria. El premio se decide por parte de un jurado independiente y de reconocido prestigio. Entre los criterios que se evaluaron fueron la excelente selección de todos los elementos editoriales de la obra y el cuidado en su edición. Este segundo volumen contó además con una versión en e-book. 
En el año 2014 nació el tercer volumen, $L a$ fiesta barroca. Los reinos de Nápoles y Sicilia (1535-1713), coordinado por Pablo González Tornel, y con el equipo de autores ya consolidado del volumen segundo (Fig. 5). Fue presentado en el mes de mayo de ese año en la Real Academia de España en Roma por Marcello Fagiolo, en la Biblioteca «Alberto Bombace» de Palermo por Maria Concetta di Natale y Marco Rosario Nobile, y en el Palazzo Zevallos de Nápoles por Giovanni Muto. También este tercer volumen contó con una versión en $e$-book. Este volumen se estructuró también en ocho capítulos, culminados

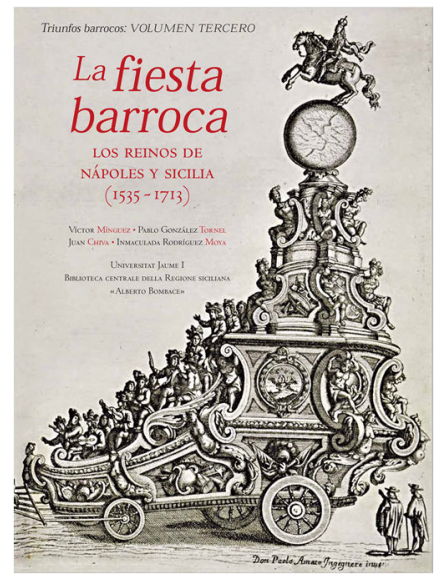
por un catálogo de setecientas tres ilustraciones que se agruparon en dos bloques: el reino de Nápoles, con quinientas cincuenta, y el reino de Sicilia, con ciento cincuenta y tres. Esta obra ha puesto al abasto de los estudiosos de la cultura festiva un conjunto de bellísimas imágenes de los dos grandes reinos del sur de la península itálica que, durante dos siglos, unieron su destino a la monarquía española. El proyecto recibió de nuevo un premio por este libro, ganando el premio a la obra mejor editada, en los XVIII Premios Nacionales de Edición Universitaria 2015, obteniendo el reconocimiento por «el cuidado de la edición, la valiosa selección de imágenes y la calidad del contenido».

El cuarto volumen de la serie, La fiesta barroca. La corte del Rey (15551808), coordinado por Inmaculada Rodríguez Moya, y con el mismo equipo de autores, se publicó también en la UJI en 2016 (Fig. 6). Para este volumen aumentamos el número de capítulos a diez, debido a la complejidad de los terri-

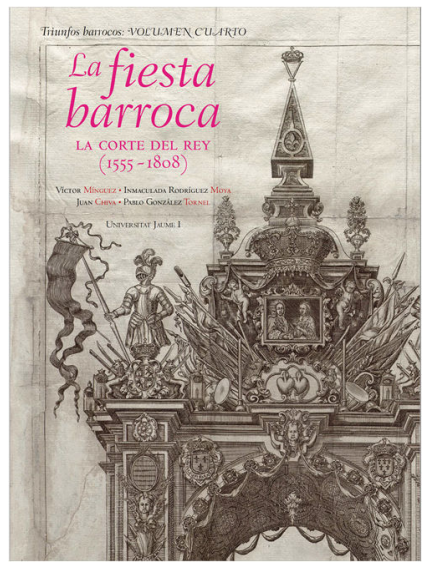
torios y temas a tratar. El catálogo contó con trescientas cuarenta y seis imágenes, de nuevo recopilando desde grabados, a acuarelas, dibujos, lienzos e incluso fotografías de algunas arquitecturas supervivientes. El volumen fue presentado en diciembre de 2017 en la Facultad de Geografía e Historia de la Universidad de Santiago de Compostela, durante la celebración del XI Congreso Nacional de la Sociedad Española de Emblemática. En esta ocasión la investigación se centró en el corazón del universo festivo hispano, la Corte, pero entendida ésta como el lugar donde el rey despliega su poder y su ceremonial. Por 
ello abordamos el despliegue de la fiesta en los diversos lugares donde residió el monarca durante largas temporadas por toda la geografía peninsular: Toledo, Madrid, Valladolid, Sevilla y los Reales Sitios, como El Escorial, Aranjuez y La Granja. Estas ciudades, palacios y jardines fueron escenario para el despliegue de una gran tipología de ceremoniales y festejos, en los que la presencia de la familia real y de la élite nobiliaria y eclesiástica propiciaron el empleo de importantes recursos económicos, la intervención de los arquitectos y artistas áulicos y el uso de espacios privilegiados.

El quinto volumen La fiesta barroca. Portugal hispánico y el imperio oceánico, coordinado por Juan Chiva Beltrán, con el mismo equipo, se publicó en el año 2018 (Fig. 7). De nuevo el contenido se estructuró en diez capítulos y el catálogo agrupó a ciento cincuenta y tres imágenes, un número menor explicable por la escasa duración del dominio español sobre los territorios portugueses peninsulares y asiáticos. El libro fue presentado en abril de 2019 en el marco del IV Simposio Internacional de Jóvenes Investigadores del Barroco Iberoamericano: las orillas del $\mathrm{Ba}$ rroco, en el entorno de la Real Academia de Extremadura de las Letras y las Artes. En este

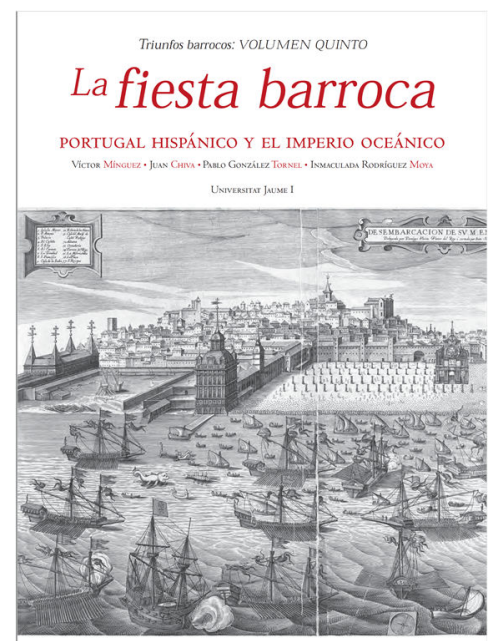
caso abordábamos la fiesta realizada en los territorios portugueses desde que, en abril de 1581, se integrara en la corona española, cuando Felipe II fue coronado en las Cortes de Tomar y hasta la pérdida efectiva del reino en diciembre de 1640 a raíz del asalto del Palacio Real de Lisboa por parte de la nobleza portuguesa y la aclamación del VIII duque de Bragança como rey. No obstante, se integraron también en el volumen imágenes precedentes relacionadas con los últimos monarcas de la casa Avís, así como posteriores al dominio español, abarcando hasta el fallecimiento de Bárbara de Braganza en 1758 en el Palacio Real de Aranjuez. Sólo así podrían entenderse las intensas relaciones entre ambas monarquías, que caracterizaron muchos de los mensajes de la fiesta durante el gobierno español, puesto que, tanto a través de la política como de los matrimonios o de las influencias culturales, ambos reinos estuvieron unidos desde el siglo XVI. El estudio incorporó también las referencias festivas de los territorios americanos y asiáticos del imperio portugués, incluyendo las manifestaciones efímeras filipinas del siglo XIX, que quedaron fuera de los volúmenes 
anteriores por pertenecer Manila al virreinato de la Nueva España, y que, tras la independencia de México, entraron en la órbita lusa.

La consolidación del proyecto a nivel editorial supuso que en este quinto volumen se planteara desde la editorial universitaria la creación de un Comité Científico externo que avalara el proyecto y que se formó con grandes especialistas en el arte, la cultura y la fiesta de la Edad Moderna, referentes para nuestro grupo: Fernando Checa Cremades (Universidad Complutense de Madrid), Maria Concetta di Natale (Università degli Studi di Palermo), María Luisa Lobato López (Universidad de Burgos), Friedrich Pollero $\beta$ (Universität Wien), Andrea Sommer-Mathis (Österreichische Akademie der Wissenschaften) y Miguel Ángel Zalama (Universidad de Valladolid).

Finalmente, el último de los volúmenes publicados recientemente -el sexto- ha sido La fiesta renacentista. El imperio de Carlos $V$ (1500-1558), coordinado por Juan Chiva, y escrito por el mismo equipo de autores más Oskar J. Rojewski (Fig. 8). La suma de un nuevo autor, miembro del equipo IHA, responde a la intención de incorporar en cada nuevo volumen a un autor joven, formado en el seno de nuestro grupo y doctorado en la Universitat Jaume I, que sea especialista también en el ámbito de la investigación en particular, y que aporte renovación y vitalidad al proyecto. Ha sido publicado en 2020, una fecha significativa para nosotros -pues se cumplen diez años del proyecto Triunfos Barrocos-e igualmente significativa para la Historia -es el quinto centenario de la coronación como emperador de Sacro Imperio Romano Germánico de Carlos V en Aquisgrán-. Su coronación tuvo lugar en el momento de máximo esplendor de la cultura renacentista y el apogeo de la fiesta pública moderna, estableciendo además un modelo de fiesta imperial carolina en todos los territorios bajo su corona a partir de los modelos italianos y borgoñones desarrollados el siglo anterior. El volumen cuenta de nuevo con diez capítulos, que parten del análisis de los modelos festivos medievales, para realizar un recorrido por los mecanismos de la propaganda de los Habsburgo, de la cultura libresca y del grabado, así como los festejos imperiales: las tres coronaciones, la boda en Sevilla, los rituales palatinos, los viajes del emperador, el ceremonial de su abdicación y finalmente el de su muerte y exequias 
fúnebres. Este contenido se completa con cuatrocientas veintidós imágenes en un catálogo unitario.

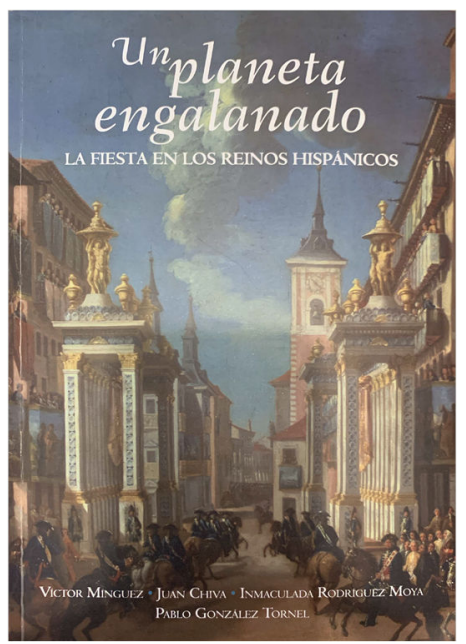

En 2019 publicamos un volumen recopilatorio titulado Un planeta engalanado. La fiesta barroca en la Monarquía Hispánica, bajo una nueva colección, la Serie Minor de Triunfos $B a-$ rrocos (Fig. 9). El objetivo era poder ofrecer una obra en un formato reducido y sin el catálogo de imágenes, puesto que los volúmenes son de gran tamaño, y que permitiera una lectura lineal de todos los volúmenes publicados hasta esa fecha, puesto que algunos ya estaban agotados en formato papel. Nuestra intención es también publicar este volumen global en inglés, para poder promoverlo entre el público internacional.

Hemos tenido también la suerte y el honor de contar en todos los volúmenes con el aval de historiadores del arte de la talla de María de los Reyes Hernández Socorro, Francesco Vergara Caffarelli, Fernando Checa, Francisco Javier Pizarro Gómez, Alfredo J. Morales, reconocidos especialistas nacionales e internacionales en la fiesta y en el ámbito de los grabados y el libro festivo. Pero hemos contado con un apoyo indispensable: Carmina Pinyana, directora de Publicacions de la Universitat Jaume I, quien ha sido responsable de convertir este proyecto en realidad, con la calidad y el cuidado que le caracterizan. Todos los volúmenes publicados hasta el momento han sido financiados gracias a los diversos proyectos que los autores han obtenido a lo largo de estos diez años, tanto proyectos específicos para los volúmenes como otros proyectos centrados también en la fiesta, puesto que los autores además han desarrollado una actividad paralela en torno a esta temática, gracias precisamente al trabajo centrado en estos volúmenes.

Podemos citar, por ejemplo, tres aportaciones importantes en forma de libro: Inmaculada Rodríguez y Víctor Mínguez, Himeneo en la Corte. Poder, representación y ceremonial nupcial en el arte y la cultura simbólica (CSIC, Madrid, 2013); Pablo González Tornel y Víctor Mínguez, Cuatro reyes para Sicilia. Proclamaciones y coronaciones en Parlemo 1700-1735 (Universitat Jaume I-Universidad de Granada, Castellón, 2016); y Pablo González Tornel, Roma hispánica. Cultura festiva española en la capital del barroco (CEEH, Madrid, 2017). Asimismo, hemos organizado numerosos congresos, jornadas y 
conferencias en torno a la fiesta renacentista y barroca, donde hemos contado con la presencia de grandes especialistas europeos y americanos. Sus resultados han sido publicados en volúmenes colectivos como: Inmaculada Rodríguez y Víctor Mínguez (eds.), Visiones de un imperio en fiesta (Fundación Carlos de Amberes, Madrid, 2016); Oskar J. Rojewski y Miroslawa Sobczynska-Szczepanska (eds.), Court, princes and festivals. Studies on the Early Modern visual culture (University of Silesia, Katowice, 2019); Inmaculada Rodríguez Moya (ed.), El rey festivo: palacios, jardines, mares y ríos como escenariso cortesanos (siglos XVI-XIX) (Imago, Valencia, 2019)

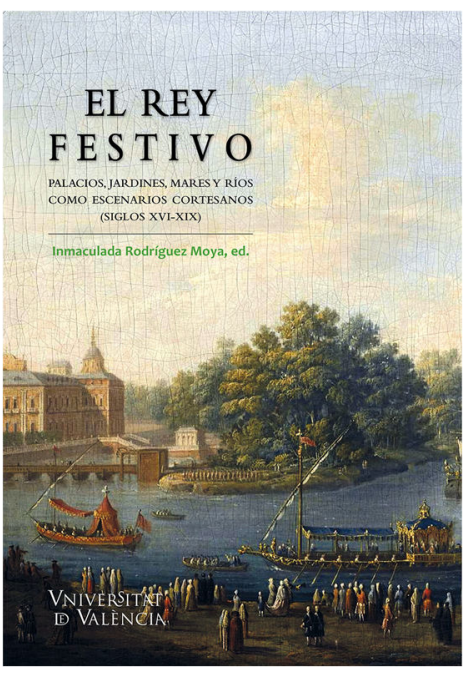
(Fig. 10); y Juan Chiva (ed.), La formación del ceremonial cortesano: los inicios de la fiesta Renacentista (Universitat de València, en prensa).

\section{CERRANDO EL CÍRCULO DEL ORBE FESTIVO}

Los restantes volúmenes de la serie, centrados en otros ámbitos territoriales y culturales de la Monarquía Hispánica, ya han sido diseñados y esperan el momento oportuno para ir sucesivamente activándose. En estos momentos -finales del año 2020- estamos trabajando en un volumen -el séptimo- sobre la Corona de Aragón: La fiesta barroca. Los reinos de Aragón y Mallorca, y el condado de Barcelona, también con diez capítulos. Además de los autores habituales, incorporamos a Antonio Gozalbo Nadal, joven investigador del grupo, y será coordinado por Pablo González Tornel. Aunque ya abordamos el reino de Valencia en el primer volumen, realizaremos una revisión de este primer trabajo y abordaremos otros territorios, además de la especificidad política y simbólica de la corona y su disolución en el periodo borbónico.

Los siguientes volúmenes estarán centrados en otros territorios importantísimos a nivel político y festivo para la corona española: La fiesta barroca. Las ciudades de Flandes (1555-1713), La fiesta barroca. La corona de Castilla y el reino de Navarra y La Fiesta barroca. El milanesado y el reino de Cerdeña, que culminarán con otro volumen recopilatorio de los triunfos barrocos, del sexto al décimo. En el objetivo del grupo está también realizar otros dos volúmenes, el onceavo y el doceavo, centrados en las ciudades satélite de la monarquía: uno para las ciudades italianas y otro para Viena, París y Londres. El 
objetivo es estudiar los espacios cortesanos de patrocinio hispánico en otras cortes europeas en ocasiones aliadas de la monarquía, que además produjeron grabados de gran calidad y belleza formal por parte de reputados grabadores. De este modo, ofreceríamos una perspectiva completa de la fiesta barroca en la monarquía Hispánica, con su carácter de artificio, espectáculo e ilusionismo, ofreciendo una imagen especular y planetaria de lo que el Imperio pretendía ser. Todos estos libros pasados, presentes y futuros, bien de la colección Triunfos Barrocos, bien resultado de los congresos organizados por IHA, han protagonizado en los últimos diez años nuestra labor investigadora y nos acompañarán también en los años venideros.

\section{BIBLIOGRAFÍA}

CHIVA BELTRÁN, J. (ed.), La formación del ceremonial cortesano: los inicios de la fiesta Renacentista, Valencia, Universitat de València, en prensa.

CHIVA BELTRÁN, J., GONZÁLEZ TORNEL, P., MÍNGUEZ CORNELLES, V. y RODRÍGUEZ MOYA, I., La fiesta barroca. Portugal hispánico y el imperio oceánico, col. «Triunfos Barrocos», vol. V, Castelló de la Plana, Universitat Jaume I, Servei de Comunicació i Publicacions, 2018.

GONZÁLEZ TORNEL, P., Roma hispánica. Cultura festiva española en la capital del barroco, Madrid, CEEH, 2017.

GONZÁLEZ TORNEL, P. y MÍNGUEZ CORNELLES, V., Cuatro reyes para Sicilia. Proclamaciones y coronaciones en Parlemo 1700-1735, Castelló de la Plana, Universitat Jaume I / Universidad de Granada, 2016. MÍNGUEZ CORNELLES, V. (ed.), Visiones de la monarquía hispánica, Castelló de la Plana, Publicaciones de la Universitat Jaume I, 2007.

MÍNGUEZ CORNELLES, V. y RODRÍGUEZ MOYA, I. (dirs.), La piedad de la Casa de Austria. Arte, dinastía y devoción, Gijón, Ediciones Trea, 2018.

MÍNGUEZ CORNELLES, V., CHIVA BELTRÁN, J., GONZÁLEZ TORNEL, P. y RODRÍGUEZ MOYA, I., Un planeta engalanado. La fiesta barroca en la Monarquía Hispánica, (Triunfos barrocos, serie minor, 1), Castelló de la Plana, Universitat Jaume I, Servei de Comunicació i Publicacions, 2019.

MÍNGUEZ CORNELLES, V., CHIVA BELTRÁN, J., GONZÁLEZ TORNEL, P., RODRÍGUEZ MOYA, I. y ROJEWSKI, O. J., La fiesta renacentista. El imperio de Carlos V (1500-1558), col. «Triunfos Barrocos», 
vol. V, Castelló de la Plana, Universitat Jaume I, Servei de Comunicació i Publicacions, 2020.

MÍNGUEZ CORNELLES, V., GONZÁLEZ TORNEL, P., CHIVA BELTRÁN, J. y RODRÍGUEZ MOYA, I., La fiesta barroca. Los reinos de Nápoles y Sicilia (1535-1713), col. «Triunfos Barrocos», vol. III, Castelló de la Plana, Universitat Jaume I, Servei de Comunicació i Publicacions, 2014.

MÍNGUEZ CORNELLES, V., GONZÁLEZ TORNEL, P., CHIVA BELTRÁN, J. y RODRÍGUEZ MOYA, I., La fiesta barroca. La corte del Rey (1555-1808), col. «Triunfos Barrocos», vol. IV, Castelló de la Plana, Universitat Jaume I, Servei de Comunicació i Publicacions, 2016.

MÍNGUEZ CORNELLES, V., GONZÁLEZ TORNEL, P. y RODRÍGUEZ MOYA, I., La fiesta barroca. El reino de Valencia (1599-1802), col. «Triunfos Barrocos», vol. I, Castelló de la Plana, Publicacions de la Universitat Jaume I, 2010.

MÍNGUEZ CORNELLES, V., GONZÁLEZ TORNEL, P., RODRÍGUEZ MOYA, I., CHIVA BELTRÁN, J., HERNÁNDEZ SOCORRO, Mª R. y PINYANA I GARÍ, $\mathrm{M}^{\mathrm{a}} \mathrm{C}$., La fiesta barroca. Los virreinatos americanos (1560-1808), col. «Triunfos Barrocos», vol. II, Castelló de la Plana, Universitat Jaume I, Servei de Comunicació i Publicacions/ Las Palmas, Universidad de las Palmas de Gran Canaria, 2012.

MÍNGUEZ CORNELLES, V. y RODRÍGUEZ MOYA, I. (eds.), Visiones de pasión y perversidad, Madrid, Fernando Villaverde Ediciones, 2014.

MÍNGUEZ, V., RODRÍGUEZ MOYA, I. y ZURIAGA SENENT, V. (eds.), El sueño de Eneas. Imágenes utópicas de la ciudad, Valencia, Generalitat Valenciana / Universitat Jaume I, 2009.

RODRÍGUEZ MOYA, I. (ed.), El rey festivo: palacios, jardines, mares y rios como escenariso cortesanos (siglos XVI-XIX), Valencia, Anejos de Imago, 2019.

RODRÍGUEZ MOYA, I. y MÍNGUEZ CORNELlES, V., Himeneo en la Corte. Poder, representación y ceremonial nupcial en el arte y la cultura simbólica. Madrid, CSIC, 2013.

RODRÍGUEZ MOYA, I y MÍNGUEZ CORNELLES, V. (eds.), Arte en los confines del imperio. Visiones hispánicas de otros mundos, Castelló de la Plana, Universitat Jaume I, 2011.

RODRÍGUEZ MOYA, I y MÍNGUEZ CORNELLES, V. (eds.), Visiones de un imperio en fiesta, Madrid, Fundación Carlos de Amberes, 2016.

RODRÍGUEZ MOYA, I y MÍNGUEZ CORNELLES, V. (eds.), Rex bellum. Visiones artísticas de guerra y conquista, Gijón, Ediciones Trea, en prensa. 
ROJEWSKI, O. J. y SOBCZYNSKA-SZCZEPANSKA, M. (eds.), Court, princes and festivals. Studies on the Early Modern visual culture, Katowice University of Silesia, 2019.

Inmaculada Rodríguez Moya
Departamento de Historia, Geografía y Arte
Facultad de Ciencias Humanas y Sociales
Universitat Jaume I
Avda. Sos Baynat, s/n - 12071 Castellón
https://orcid.org/0000-0003-2481-1855
mrodrigu@uji.es
Víctor Mínguez Cornelles
Departamento de Historia, Geografía y Arte
Facultad de Ciencias Humanas y Sociales
Universitat Jaume I
Avda. Sos Baynat, s/n - 12071 Castellón
https:/orcid.org/0000-0002-9330-8789
minguez@uji.es

